\title{
Socioeconomic position, John Henryism, and incidence of acute myocardial infarction in Finnish men
}

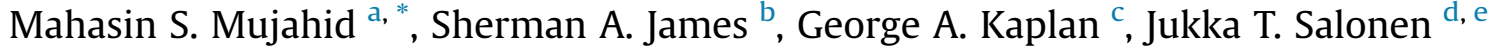 \\ a Division of Epidemiology, School of Public Health, University of California, 105 Haviland Hall, Berkeley, CA 94720-7358, United States \\ ${ }^{\mathrm{b}}$ Department of Epidemiology, Rollins School of Public Health, Emory University, 1518 Clifton Rd., Atlanta, GA 30322, United States \\ ${ }^{\mathrm{c}}$ Department of Epidemiology, School of Public Health, University of Michigan, Ann Arbor, MI, United States \\ d Metabolic Analytical Services Inc., Helsinki, Finland \\ e Department of Public Health, Faculty of Medicine, University of Helsinki, Helsinki, Finland
}

\section{A R T I C L E I N F O}

\section{Article history:}

Received 27 April 2016

Received in revised form

22 November 2016

Accepted 24 November 2016

Available online 25 November 2016

\section{Keywords:}

John Henryism

Socioeconomic position

Cardiovascular disease

\begin{abstract}
A B S T R A C T
Previous cross-sectional studies examining whether John Henryism (JH), or high-effort coping with socioeconomic adversity, potentiates the inverse association between socioeconomic position (SEP) and cardiovascular health have focused mainly on hypertension in African Americans. We conducted the first longitudinal test of this hypothesis on incident acute myocardial infarction (AMI) using data from the Kuopio Ischemic Heart Disease Risk Factor Study in Finland ( $N=1405$ men, 42-60 years). We hypothesized that the expected inverse gradient between SEP and AMI risk would be stronger for men scoring high on JH than for those scoring low. John Henryism was measured by a Finnish version of the JH Scale for Active Coping. Four different measures of SEP were used: childhood SEP, education, income, and occupation. AMI hazard ratios (HR) by SEP and JH were estimated using COX proportional hazard models, before and after adjustment for study covariates. 205 cases of AMI occurred over a median of 14.9 years. Men employed in lower rank (farmer, blue-collar) occupations who scored high on JH had significantly higher age-adjusted risks of AMI than men in higher rank (white-collar) occupations ( $\mathrm{HR}=3.14,95 \% \mathrm{CI}$ : $1.65-5.98$ for blue collar; $\mathrm{HR}=2.33,95 \% \mathrm{CI}$ : $1.04-5.22$ for farmers) who also scored high on JH. No socioeconomic differences in AMI were observed for men who scored low on JH (HR $=1.36,95 \% \mathrm{CI}: 0.74$ -2.47 for blue collar; HR $=0.93,95 \% \mathrm{CI}: 0.59-1.48$ for farmers; $\mathrm{p}=0.002$ for the SEP $\times \mathrm{JH}$ interaction). These findings persisted after adjustment for sociodemographic, behavioral, and biological factors. Results for other SEP measures were in the same direction, but did not reach statistical significance. Repetitive high-effort coping with adversity (John Henryism) was independently associated with increased risk for AMI in Finnish men, underscoring the potential relevance of the John Henryism hypothesis to CVD outcomes other than hypertension and to populations other than African Americans.
\end{abstract}

() 2016 Published by Elsevier Ltd.

\section{Introduction}

Coronary heart disease (CHD) remains the leading cause of death in developed countries and is also a growing contributor to morbidity and mortality from non-communicable diseases in developing nations (Lim et al., 2012; Lozano et al., 2012). In developed countries, the burden of CHD is disproportionately large among persons in lower socioeconomic positions (SEP) (Havranek

\footnotetext{
* Corresponding author.

E-mail addresses: mmujahid@berkeley.edu (M.S. Mujahid), sherman.james@ emory.edu (S.A. James), gkaplan@umich.edu (G.A. Kaplan), jtsalonen@ windowslive.com (J.T. Salonen).
}

et al., 2015; Kaplan and Keil, 1993). Whether measured by income, education, or occupation, the well documented inverse gradient between SEP and CHD risk is often attenuated, but rarely completely eliminated, after controlling for known biological and behavioral risk factors (Havranek et al., 2015; Kaplan and Keil, 1993; Lynch et al., 1996). The robustness of the association could be due to a greater biological vulnerability to CHD among lower SEP adults exposed to very adverse social or economic conditions during critical stages of development (Barker, 1995; Kaplan and Salonen, 1990; Power and Matthews, 1997), or the excess risk could be due to accelerated aging of the cardiovascular system during young adulthood resulting from a strong predisposition by some low SEP individuals to repeatedly engage in high-effort coping with difficult 
life stressors (McEwen and Gianaros, 2010). James and colleagues (James et al., 1983, 1992, 1987) call such high-effort coping "John Henryism," after the 19th century African American unskilled laborer, John Henry, who allegedly defeated a machine in an epic "steel-driving" contest, but then dropped dead from complete exhaustion (Johnson, 1929).

James et al. defined John Henryism as a "strong behavioral predisposition to engage in high-effort coping with social or economic adversity." Some common examples of such adversity include financial hardship, overwork, job uncertainty, unemployment, and recurring exposure to discrimination based on race, ethnicity, gender, or SEP. Building on both laboratory (Obrist et al., 1978; Ostfeld and Shekelle, 1967) and field studies (D'Atri and Ostfeld, 1975; Harburg et al., 1973; Kasl and Cobb, 1970) investigating blood pressure (BP) responses to social or economic adversity, James et al. hypothesized that repetitive, high-effort coping with such adversity potentiates risk for hypertension among the most economically disadvantaged individuals (James et al., 1983, 1992, 1987). The John Henryism hypothesis, as it is called, is empirically supported when there is a statistically significant interaction between John Henryism and SEP such that the magnitude of the association between SEP and the cardiovascular disease outcome (e.g., mean BP or hypertension prevalence) is stronger among persons scoring high on John Henryism compared to those scoring low.

In the current literature, epidemiological investigations of the John Henryism hypothesis have focused primarily (but not exclusively) on African Americans; published findings have been mixed. In three, separate cross-sectional studies conducted in eastern North Carolina, James et al. found support for the hypothesis among 17-60 year old Black men (James et al., 1983), 21-50 year old Black men and women (James et al., 1987), and 25-50 year old Black men and women (James et al., 1992). Dressler et al. observed a gender (but not SEP) interaction between John Henryism and mean BP in a study of 25-65 year old Black men and women in Tuscaloosa, Alabama (Dressler et al., 1998). McKetney and Ragland, in a study of blood pressure variation among 18-30 year old Whites and Blacks in the baseline Coronary Artery Risk Development in Young Adults Study (CARDIA) sample, did not find support for the hypothesis (McKetney and Ragland, 1996). Subramanyam et al., using baseline data for 18-95 year old African Americans in the Jackson Heart Study, found a borderline, statistically significant John Henryism $\times$ income interaction for men, but not women (Subramanyam et al., 2013). The degree to which differences in geographical location, sample differences in age distributions, the choice of SEP measures, or approaches to measuring BP account for these mixed findings is not known.

To date, all previous investigations of the John Henryism hypothesis have been cross-sectional and only a few have considered non-African Americans (Duijkers et al., 1988; Haritatos et al., 2007: Logan et al., 2015), though a predisposition to engage in high-effort coping with difficult life conditions is certainly not unique to African Americans. The current prospective study provides an opportunity to test the generality of the John Henryism hypothesis to a cardiovascular outcome other than hypertension, specifically acute myocardial infarction, and to a cultural setting outside of the U.S. We tested the hypothesis that John Henryism will potentiate the longitudinal association between socioeconomic position and acute myocardial infraction. To be comprehensive, we used four measures of socioeconomic position (adulthood education, income, and occupation, and childhood socioeconomic position). In keeping with prior confirmatory results focused on hypertension (James et al., 1983, 1992, 1987), our a priori hypothesis was the following: the inverse association between socioeconomic position and acute myocardial infarction would be stronger among those scoring high on John Henryism compared to those scoring low.

\section{Methods}

\subsection{Study population}

We tested the John Henryism hypothesis in a prospective population-based age-stratified sample of Finnish men residing in the city of Kuopio and its surrounding rural communities. Two cohorts ( $\mathrm{N}=2682$ of 3235 eligible men, $82.9 \%$ response rate) of men were recruited into the Kuopio Ischemic Heart Disease Risk Factor (KIHD) Study between March 1984 and December 1989 (Salonen, 1988). The first cohort consisted of men aged 54 years at baseline, and 1166 (83.3\% of age-eligibles) agreed to participate. The second cohort consisted of men ages $42,48,54$, and 60 years at baseline, and 1516 ( $82.6 \%$ of age-eligibles) agreed to participate. A more detailed description of recruitment and sampling protocols for the KIHD Study is reported elsewhere (Salonen, 1988). In the current study, 677 men were excluded if they had a prior history of AMI, angina pectoris, nitroglycerine use, or positive findings of angina based on the London School of Hygiene Cardiovascular Questionnaire (Rose et al., 1982), leaving 2005 who met our study eligibility criteria. Of these men an additional 385 were excluded due to missing data on the study exposure. Men missing data on John Henrysim were more likely to be older and to have lower education and worse self-reported health (all p's $<0.001$ ). An additional 215 were excluded due to missing data on all other study covariates, representing less than $2 \%$ missingness on these covariates. The final analytic sample was $\mathrm{N}=1405$.

\subsection{Study outcome}

The study outcome was having a fatal or non-fatal AMI event during the 14.9 years (March 1986 to March 2002) of follow-up. Information on non-fatal AMI (if first-time event) and coronary deaths was obtained from patient linkages (using a social security equivalent personal identification number) to the FINMONICA registry established under the World Health Organization Monitoring of Trends and Determinants of Cardiovascular Disease Project (Tuomilehto et al., 1992). The province of Kuopio was one of three geographic sites in the FINMONICA catchment area, which also included North Karelia in eastern Finland and Turka/Loimaa in southwestern Finland (Tuomilehto et al., 1992). Kuopio participated in the registry through January 1993. During this time, non-fatal events were diagnosed using the WHO MONICA manual and were determined using data from electrocardiography, cardiac enzymes, symptom and necropsy findings, as well as chart reviews. AMI was defined as first attack diagnosed within 28 days from the onset of symptoms and excluded cases in which a silent myocardial infarction was detected later. Fatal events were classified as cases in which ICD codes (version 8) 410-414 or 795 appeared on the death certificate as main or other cause of death. Additional details are provided elsewhere (Tuomilehto et al., 1992). Fatal and non-fatal CVD events occurring after January 1993 were obtained by computer linkage to the national hospital discharge and death certificate registry and events were classified by an internist trained in a protocol identical to the criteria established by FINMONICA (Lakka et al., 2002; Tuomilehto et al., 1992).

\subsection{Exposures}

John Henryism was measured by a 10 -item subset of the original 12-item English scale (James et al., 1987) that was translated into Finnish (Table 1). Three illustrative items from the John Henryism scale are: "Once I make up my mind to do something, I stay with it until the job is completely done"; "When things don't go the way I want them to, that just makes me work even harder"; and "Hard 
Table 1

John Henrysim survey items.

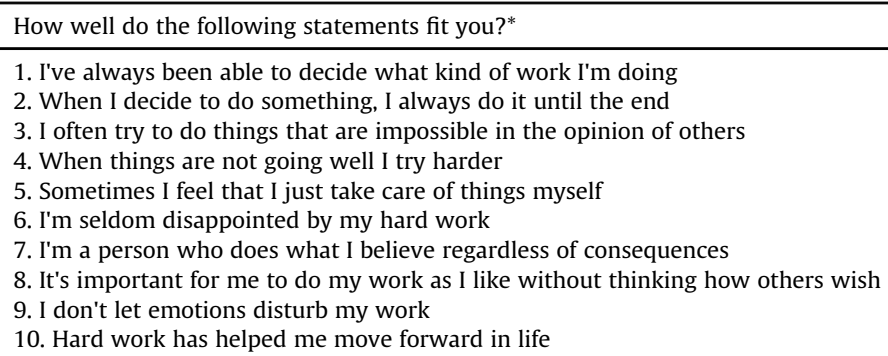

*responses are based on a 5 -point likert scale ( $1=$ Completely True; 2 = Somewhat True; $3=$ I can't say; $4=$ Somewhat False; $5=$ Completely False).

work has really helped me to get ahead in life." Responses to each item range from 1 to 5 (completely false $=1$ and completely true $=5$ ); the total John Henryism score was obtained by summing responses to the 10 items. Individuals were classified as "high" on John Henryism if their total score was greater than the median of 37 (range $=19-50$ ). If no more than two scale items had missing values, scores for these items were imputed based on the individual's median score for the remaining items. The Cronbach alpha reliability coefficient (internal consistency measure) for the Finnish language version of the John Henryism Scale was 0.75, comparable to U.S.-based studies (James et al., 1987, 1992).

Four indicators of socioeconomic position (SEP) were used. These were education (low: < 6 years, medium: 7-11 years, and high: 12 plus); income (tertiles: $<\$ 18,000 ; \$ 18,000-\$ 27,000$; $>\$ 27,9000$ in finmarks); occupation (blue-collar, white-collar, and farmer); and childhood SEP, a summary measure in tertiles of reported family SEP resources on the following items when participants were 10 years of age: parents' education and occupation, number of rooms in the home, size of the parents' farm, and perception of family wealth (Kaplan et al., 2001; Lynch et al., 1994a). Higher tertiles, for all measures, represent better socioeconomic conditions.

\subsection{Covariates}

Key demographic and psychosocial characteristics of study participants were obtained from the KIHD baseline questionnaire including age, marital status, Type A behavior, hopelessness, workplace demands, co-worker support, and supervisor support. Type A behavior, which shares a strong achievement orientation with John Henryism (Everson et al., 1997a) was measured by the Jenkins Activity Survey (Lakka et al., 1994). Hopelessness, which in prior work (Ihanainen et al., 1989) predicted carotid atherosclerosis progression in the KIHD cohort, was measured by the 2 item Hopelessness Scale. Work-place demands, a predictor of AMI and cardiovascular as well as all-cause mortality in previous work (Everson et al., 1997b) on the KIHD cohort, was measured by 11 items denoting physical (i.e. heavy physical work, repetitive straining of muscles, exposure to noise) as well as mental demands of the job. As in prior work (Everson et al., 1997b), total work demand scores were summed and divided into tertiles. If fewer than 2 work demand items had missing data, the mean score for non-missing items were substituted. The alpha coefficient for the work demands scale was an acceptable 0.78 .

The measurement of relevant health behaviors and self-rated health followed approaches used in previous KIHD (Lakka et al., 1994; Lynch et al., 1997). Cigarette smoking status was defined by 5 categories: never smoker, former smoker, and for current smokers, tertiles of exposure based on number of packs smoked per year. Alcohol consumption was categorized as non-drinkers vs. drinkers, with the latter further divided into tertiles of consumption based on dietary recall of grams of alcohol consumed over a 4day period and also during the previous 12 months. Physical activity was expressed as duration (average minutes per week) of leisure-time physical activity during the previous 12-months (Lakka et al., 1994). Biological covariates included body mass index (BMI), hypertension, low-density lipoprotein (LDL), highdensity lipoprotein (HDL), total cholesterol, serum blood glucose, and plasma fibrinogen. These data were collected at baseline using methods described in detail elsewhere (Salonen et al., 1991, 1992; Wilson et al., 1993).

\subsection{Statistical analysis}

First, we examined the distribution of study covariates overall, and by AMI and mean John Henryism score. To identify potential confounders, we also examined AMI incidence rates by study covariates and assessed bivariate associations between study covariates and John Henryism. To test the hypothesis that the inverse gradient between SEP and AMI varies by level of John Henryism, we ran a series of sequential Cox proportional hazards models after confirmation of the proportional hazards assumption. In Model 1, we included age, SEP, John Henryism, and the interaction between SEP and John Henryism. Marital status and psychosocial factors (Type A behavior and hopelessness) were added in Model 2. Health behaviors (smoking, alcohol consumption, physical activity) were added in Model 3. Biological risk factors (BMI, hypertension, HDL, LDL, total cholesterol, serum blood glucose, and plasma fibrinogen) along with self-rated health were included in Model 4. Hazard ratios (HR) and 95\% confidence intervals were derived from the models and used to test hypotheses. The model sequence was repeated for each of the four SEP measures: education, income, occupation, childhood SEP. In final models, we tested for multicollinearity by assessing the variance inflation factors and tolerance and found that all values were within conservative estimates of these values (TOL $>0.2$ and $\mathrm{VIF}<5$ ). All analyses were performed using SAS V9.4 Programming Language.

\section{Results}

During a median of 14.9 years of follow-up (range 1-18 years), $14.6 \%$ of participants had an AMI, corresponding to 205 cases and 19,506 person-years. Table 2 shows characteristics of the analytic sample and the incidence of AMI by study covariates and mean John Henryism score. Incidence rates of AMI were associated in the expected direction with most of these well-known sociodemographic, psychosocial, health behaviors and biological risk factors. For example, incidence of AMI was highest among older adults and those with lower education and income, blue-collar workers and farmers. Individuals with higher John Henryism and hopelessness 
Table 2

Sample characteristics, incidence rates of MI per 1000 person years, and mean John Henryism $(\mathrm{N}=1405)$.

\begin{tabular}{|c|c|c|c|c|}
\hline & $\mathrm{N}$ & $\%$ & $\begin{array}{l}\text { IR of MI per } 1000 \text { person years } \\
\text { (14.9 yrs follow-up) }\end{array}$ & $\begin{array}{l}\text { Mean John Henryism } \\
(\text { mean }=36.62)\end{array}$ \\
\hline \multicolumn{5}{|l|}{ Age (years) } \\
\hline 42 yrs & 271 & 19.29 & 5.65 & 35.94 \\
\hline $48 \mathrm{yrs}$ & 254 & 18.08 & 9.21 & 36.06 \\
\hline 54 yrs & 698 & 49.68 & 12.20 & 36.72 \\
\hline 60 yrs & 182 & 12.95 & 13.48 & 37.31 \\
\hline p-trend & & & $<0.001$ & 0.001 \\
\hline \multicolumn{5}{|l|}{ Education (years) } \\
\hline$\leq 6$ yrs & 301 & 21.42 & 15.04 & 37.27 \\
\hline $7-11$ yrs & 802 & 57.08 & 10.15 & 36.47 \\
\hline 12 yrs or higher & 302 & 21.49 & 7.05 & 35.95 \\
\hline p-trend & & & $<0.001$ & 0.002 \\
\hline \multicolumn{5}{|c|}{ Income (tertiles): Mean $(s t d)=136,810(73,434)$} \\
\hline Low $(<\$ 18,000$ finmarks $)$ & 468 & 33.31 & 13.11 & 37.22 \\
\hline Middle $(\$ 18,000-\$ 27,900)$ & 464 & 33.02 & 11.40 & 36.26 \\
\hline High $(>\$ 27,900)$ & 473 & 33.67 & 7.13 & 36.11 \\
\hline p-trend & & & $<0.001$ & $<0.001$ \\
\hline \multicolumn{5}{|l|}{ Occupation } \\
\hline Blue-collar & 580 & 41.28 & 12.50 & 36.51 \\
\hline White-collar & 649 & 46.19 & 7.20 & 36.32 \\
\hline Farmer & 176 & 12.53 & 16.56 & 37.36 \\
\hline$p$-value & & & $<0.001$ & 0.230 \\
\hline \multicolumn{5}{|l|}{ Childhood SEP } \\
\hline Low & 448 & 31.89 & 11.69 & 36.77 \\
\hline Middle & 636 & 45.27 & 10.33 & 36.68 \\
\hline High & 321 & 22.85 & 9.23 & 35.90 \\
\hline$p$-trend & & & 0.216 & 0.028 \\
\hline \multicolumn{5}{|l|}{ Employment } \\
\hline Yes & 320 & 22.78 & 9.84 & 37.09 \\
\hline No & 1085 & 77.22 & 12.96 & 36.36 \\
\hline$p$-value & & & 0.090 & 0.026 \\
\hline \multicolumn{5}{|l|}{ Marital Status } \\
\hline Marred/living with a couple & 1236 & 87.97 & 10.41 & 36.51 \\
\hline Divorced/widowed & 81 & 5.77 & 12.00 & 37.69 \\
\hline Single & 88 & 6.26 & 10.65 & 35.76 \\
\hline$p$-value & & & 0.888 & 0.683 \\
\hline \multicolumn{5}{|l|}{ John Henrysim } \\
\hline Low & 695 & 49.47 & 8.99 & $N / A$ \\
\hline High & 710 & 50.53 & 12.00 & \\
\hline$p$-value & & & 0.040 & \\
\hline \multicolumn{5}{|l|}{ Hopelessness (tertiles) } \\
\hline Low & 511 & 36.37 & 8.00 & 37.04 \\
\hline Middle & 325 & 23.13 & 8.50 & 36.02 \\
\hline High & 569 & 40.5 & 14.08 & 36.37 \\
\hline$p$-trend & & & $<0.001$ & 0.036 \\
\hline \multicolumn{5}{|l|}{ Type A Behavior (tertiles) } \\
\hline Low & 462 & 32.88 & 12.34 & 35.09 \\
\hline Middle & 483 & 34.38 & 9.37 & 36.53 \\
\hline High & 460 & 32.74 & 9.91 & 37.97 \\
\hline$p$-trend & & & 0.181 & $<0.001$ \\
\hline Workplace Demands & & & & \\
\hline Low & 1030 & 73.31 & 10.86 & 36.43 \\
\hline High & 375 & 26.69 & 9.55 & 36.79 \\
\hline$p$-value & & & 0.424 & 0.252 \\
\hline Supervisor Support & & & & \\
\hline Low & 308 & 21.92 & 10.03 & 36.46 \\
\hline Middle & 577 & 41.07 & 10.28 & 36.41 \\
\hline High & 520 & 37.01 & 11.05 & 36.71 \\
\hline$p$-trend & & & 0.580 & 0.424 \\
\hline Co-worker Support & & & & \\
\hline Low & 436 & 31.03 & 10.94 & 36.88 \\
\hline Middle & 337 & 23.99 & 10.34 & 36.49 \\
\hline High & 632 & 44.98 & 10.30 & 36.31 \\
\hline p-trend & & & 0.718 & 0.079 \\
\hline Self-rated Health & & & & \\
\hline Good/Very Good & 1301 & 92.6 & 9.49 & 36.43 \\
\hline Fair/Poor & 104 & 7.4 & 25.2 & 37.75 \\
\hline p-value & & & $<0.001$ & 0.011 \\
\hline Smoking status & & & & \\
\hline Never & 418 & 29.75 & 9.65 & 36.78 \\
\hline Former & 543 & 38.65 & 8.62 & 36.25 \\
\hline Low & 158 & 11.25 & 7.07 & 36.01 \\
\hline Medium & 163 & 11.6 & 18.04 & 36.55 \\
\hline & & & & ontinued on \\
\hline
\end{tabular}


Table 2 (continued)

\begin{tabular}{|c|c|c|c|c|}
\hline & $\mathrm{N}$ & $\%$ & $\begin{array}{l}\text { IR of MI per } 1000 \text { person years } \\
\text { ( } 14.9 \text { yrs follow-up) }\end{array}$ & $\begin{array}{l}\text { Mean John Henryism } \\
(\text { mean }=36.62)\end{array}$ \\
\hline High & 123 & 8.75 & 18.41 & 37.57 \\
\hline p-trend & & & $<0.001$ & 0.393 \\
\hline \multicolumn{5}{|l|}{ Alcohol (tertiles) } \\
\hline Non-drinker & 163 & 11.6 & 14.77 & 37.25 \\
\hline Low & 408 & 29.04 & 10.36 & 36.02 \\
\hline Middle & 420 & 29.89 & 8.04 & 36.70 \\
\hline High & 414 & 29.47 & 11.62 & 36.57 \\
\hline p-trend & & & 0.396 & 0.959 \\
\hline \multicolumn{5}{|l|}{ Physical Activity } \\
\hline Low & 467 & 33.24 & 10.64 & 36.38 \\
\hline Middle & 469 & 33.38 & 9.57 & 36.56 \\
\hline High & 469 & 33.38 & 11.34 & 36.65 \\
\hline p-trend & & & 0.699 & 0.408 \\
\hline \multicolumn{5}{|l|}{ BMI $\left(\mathrm{kg} / \mathrm{m}^{2}\right)$} \\
\hline Normal/Underweight & 439 & 31.25 & 7.27 & 36.03 \\
\hline Overweight & 740 & 52.67 & 11.08 & 36.59 \\
\hline Obese & 226 & 16.09 & 15.20 & 37.31 \\
\hline p-trend & & & $<0.001$ & 0.002 \\
\hline \multicolumn{5}{|l|}{ Hypertension } \\
\hline Yes & 496 & 35.3 & 15.23 & 36.57 \\
\hline No & 909 & 64.7 & 8.12 & 36.51 \\
\hline p-value & & & $<0.001$ & 0.829 \\
\hline \multicolumn{5}{|l|}{ HDL (tertiles) } \\
\hline Low & 466 & 33.17 & 13.59 & 36.27 \\
\hline Middle & 459 & 32.67 & 10.9 & 36.67 \\
\hline High & 480 & 34.16 & 7.3 & 36.65 \\
\hline p-trend & & & $<0.001$ & 0.246 \\
\hline \multicolumn{5}{|l|}{ LDL (tertiles) } \\
\hline Low & 467 & 33.24 & 5.58 & 36.10 \\
\hline Middle & 474 & 33.74 & 10.28 & 36.66 \\
\hline High & 464 & 33.02 & 15.98 & 36.83 \\
\hline p-trend & & & $<0.001$ & 0.029 \\
\hline \multicolumn{5}{|c|}{ Total cholesterol (tertiles) } \\
\hline Low & 470 & 33.45 & 5.64 & 36.47 \\
\hline Middle & 466 & 33.17 & 11.33 & 36.45 \\
\hline High & 469 & 33.38 & 14.81 & 36.66 \\
\hline p-trend & & & $<0.001$ & 0.584 \\
\hline \multicolumn{5}{|c|}{ Blood Glucose (tertiles) } \\
\hline Low & 441 & 31.39 & 8.63 & 36.29 \\
\hline Middle & 494 & 35.16 & 9.37 & 36.35 \\
\hline High & 470 & 33.45 & 13.53 & 36.94 \\
\hline -trend & & & 0.007 & 0.050 \\
\hline \multicolumn{5}{|l|}{ Fibrinogen (tertiles) } \\
\hline Low & 469 & 33.38 & 6.61 & 36.38 \\
\hline Middle & 468 & 33.31 & 10.67 & 36.35 \\
\hline High & 468 & 33.31 & 14.6 & 36.85 \\
\hline p-trend & & & $<0.001$ & 0.161 \\
\hline
\end{tabular}

scores also had higher incidence of AMI (p-values $<0.05$ ). Increased AMI incidence was associated with increased smoking, BMI, LDL, total cholesterol, blood glucose, and plasma fibrinogen, and with decreased HDL (all p-values <0.001). Individuals reporting poor/ fair self-rated health, and those with hypertension also had higher incidence AMI ( $\mathrm{p}$-values $<0.001$ ). There were no bivariate associations between AMI and childhood SES, employment status, marital status, Type A behavior, workplace demands, supervisor support, co-worker support, alcohol consumption, or physical activity.

Mean John Henryism scores were higher among older adults, the unemployed, and those with lower income, education, and childhood socioeconomic position (all p-values $<0.03$ ). Mean John Henryism score was highest among those with high type A behavior scores. Mean John Henryism scores were also highest among those with low hopelessness scores and among those who were obese and had high LDL (all p-values $<0.05$ ).

Fig. 1 shows the results of the model sequence testing the hypothesis that the inverse association between SEP and AMI would be stronger for men scoring high on John Henryism than those scoring low. Model 1 includes age, John Henryism, SEP, and the interaction between John Henryism and SEP. Models 2, 3, and 4, additionally adjust for sociodemographic/psychosocial factors (hopelessness, type A behavior, Model 2), health behaviors (smoking, alcohol consumption, physical activity, Model 3) and biological risk factors/self-rated health (self-rated health, BMI, hypertension, HDL, LDL, total cholesterol, serum blood glucose, and plasma fibrinogen, Model 4). A statistically significant interaction between John Henryism and SEP, in age-adjusted models (Model 1) was observed for occupational status. Among individuals with high John Henryism, farmers and blue-collar workers had a higher rate of AMI compared to white-collar workers ( $\mathrm{HR}=3.14,95 \% \mathrm{CI}$ : 1.65-5.98 for blue-collar; $\mathrm{HR}=2.33,95 \% \mathrm{CI}$ : $1.04-5.22$ for farmers). In contrast, there was no statistically significant association between occupational status and AMI among men scoring low on John Henryism ( $\mathrm{HR}=1.36,95 \% \mathrm{CI}$ : 0.74, 2.47 for farmers; $\mathrm{HR}=0.93,95 \% \mathrm{CI}: 0.59,1.48$ for blue collar). Additional adjustment for psychosocial factors (among high John Henryism: HR $=3.06$, 95\% CI: $1.60,5.84$ for blue-collar; $\mathrm{HR}=2.37,95 \% \mathrm{CI}$ : $1.06,5.32$ for farmers) and health behaviors (among high John Henryism: $\mathrm{HR}=2.98,95 \% \mathrm{CI}: 1.56,5.70$ for blue-collar; $\mathrm{HR}=2.65,95 \% \mathrm{CI}: 1.18$, 5.95 for farmers) reduced these associations only slightly. The significant John Henryism by Occupation interaction persisted in 

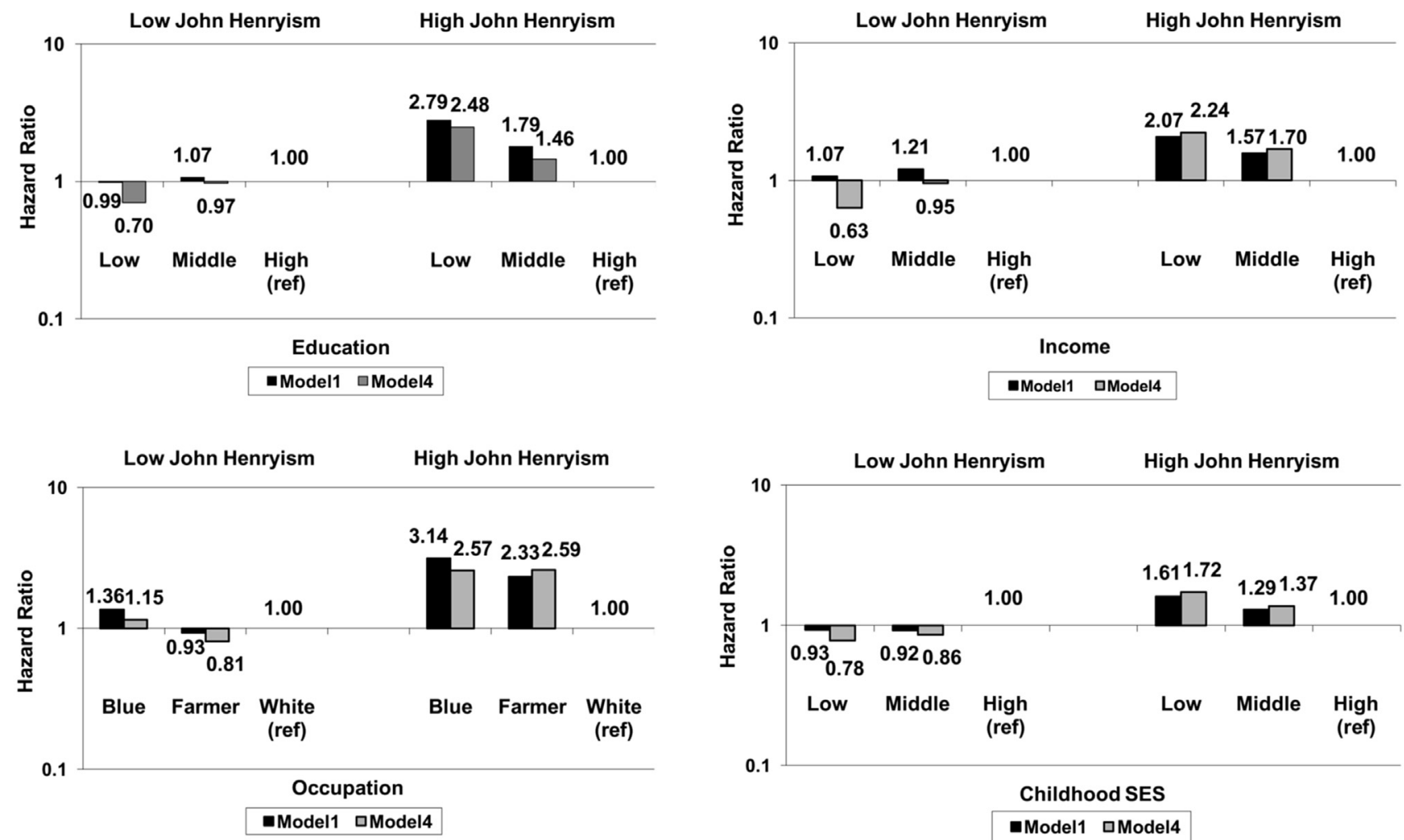

Model 1: age, SES, John Henryism, SES*John Henryism

Model 4: Model 1+ marital status, hopelessness, Type A behavior, self-rated health, alcohol consumption, smoking status, BMI, HDL, LDL, total cholesterol, serum blood glucose, fibrinogen

p-values for Education Interaction Term: $\mathrm{p}=0.084$ for Model 1, $\mathrm{p}=0.120$ for Model 4

p-values for Income Interaction Term: $\mathrm{p}=0.154$ for Model 1, $\mathrm{p}=0.107$ for Model 4

p-values for Occupation Interaction Term: $\mathrm{p}=0.002$ for Model 1, $\mathrm{p}=0.010$ for Model 4

$\mathrm{p}$-values for Childhood SES Interaction Term: $\mathrm{p}=0.481$ for Model $1, \mathrm{p}=0.407$ for Model 4

Fig. 1. Adjusted relative hazard of acute myocardial infarction by John Henryism and measures of SES.

Model 4 with additional adjustment for biological risk factors and self-rated health (among high John Henryism: $\mathrm{HR}=2.57,95 \% \mathrm{CI}$ : 1.34, 4.94 for blue-collar; $\mathrm{HR}=2.59,95 \% \mathrm{CI}: 1.14,5.88$ for farmers). There were no statistically significant interactions between John Henryism and other SEP measures (education, income, and childhood SEP) in age-adjusted models (Model 1), although trends were in the hypothesized direction.

Because John Henryism by SEP interactions were statistically significant only for occupation, we examined this association further by considering additional adjustments for employment status, workplace demands, supervisor support, and co-worker support. Associations remained similar to those in Model 4: among individuals with high John Henryism, farmers and bluecollar workers had a higher risk of AMI than white-collar workers $(\mathrm{HR}=2.53,95 \% \mathrm{CI}: 1.30,4.91$ for blue-collar; $\mathrm{HR}=2.55,95 \% \mathrm{CI}: 1.12$, 5.82 for farmers). There was no statistically significant association between occupational status and AMI among individuals with low John Henryism ( $\mathrm{HR}=0.87,95 \% \mathrm{CI}$ : 0.54, 1.43 for blue-collar; $\mathrm{HR}=1.19,95 \% \mathrm{CI}: 0.64,2.21$ for farmers). We also adjusted for the other SEP measures (education, income, and childhood SEP) and found very little change in the strength of the interaction between John Henryism and occupation on AMI risk (among high John Henryism: $\mathrm{HR}=2.52,95 \% \mathrm{CI}: 1.30,4.91$ for blue-collar; $\mathrm{HR}=2.30,95 \% \mathrm{CI}: 1.00,5.27$ among farmers). Other significant covariates in this final model included workplace demands, smoking status, self-rated health, hypertension, and blood glucose, all in the expected direction.

\section{Discussion}

In this first, longitudinal test of the John Henryism hypothesis, we found that effortful, active coping, i.e. John Henryism, with socioeconomic adversity potentiated the inverse association between occupation and incidence of acute myocardial infarction (AMI) in a population-based sample of middle-aged Finnish men. Among men with high John Henryism, farmers and blue-collar workers had over a two-fold higher rate of AMI than men in white-collar occupations, an association that persisted after adjustment for established behavioral, psychological, and biological risk factors for CHD. In keeping with the John Henryism hypothesis, no association between occupational status and AMI for men scoring low on John Henryism was observed.

This is the first study to test the John Henryism hypothesis in relation to AMI. Prior epidemiological tests of the hypothesis have focused primarily on mean blood pressure or hypertension prevalence (James et al., 1983, 1987; McKetney and Ragland, 1996; Subramanyam et al., 2013). Hence, the current study is an important extension of this prior work because it investigates incident cardiovascular events that may result from poorly controlled hypertension and for which there is strong evidence of an etiologic role for socioeconomic and psychosocial stressors (Chobanian et al., 2003; Everson-Rose and Lewis, 2005; Havranek et al., 2015). A focus on AMI also supports a growing body of literature on allostatic load, which documents the physiologic consequences of repeated or chronic exposure to stress (Seeman et al., 2001a). The 
potential stress of engaging in high-effort coping in the face of significant adversity has been demonstrated in previous work (Adams et al., 1998; Merritt et al., 2004; Wright et al., 1996). As an example, in a laboratory-based study of cardiovascular reactivity to a racial stressor among 58 healthy Black men, Merritt and colleagues found that low education-high John Henryism men had significantly higher cardiovascular reactivity and a more prolonged return to baseline values than men scoring high on both education and John Henryism (Merritt et al., 2004).

One of the strengths of the current study is our ability to statistically control, in a prospective study design, for a comprehensive set of risk factors for heart disease. In our primary analyses, we included two psychosocial measures, hopelessness and Type A behavior, because they were potential confounders of our hypothesized associations. Previous literature has established associations between these factors and John Henryism and AMI (Everson et al., 1997a; Everson-Rose and Lewis, 2005), and our bivariate associations confirmed these associations in our study population. Type A Behavior in particular, represents a psychological predisposition with a strong achievement orientation somewhat similar to that found in John Henryism. However, early work assessing measurement properties of the John Henryism Scale established that the John Henryism Scale is unidimensional, internally consistent, and has a distinctly different pattern of associations with background socioeconomic variables like education and occupation than Type A Behavior (Stanton et al., 2010; Weinrich et al., 1988). The fact that our results were robust to the statistical control of Type A behavior scores is consistent with the notion that John Henryism and Type A Behavior measure different things.

We also adjusted for an extensive set of behavioral, biological and other psychosocial variables in fully-adjusted models which reduces the likelihood of major residual confounding. Specifically, our findings were robust to controls for age, marital status, employment status, education, income, childhood SEP, hopelessness, Type A behavior, self-rated health, alcohol consumption, smoking status, BMI, HDL, LDL, total cholesterol, serum blood glucose, fibrinogen, workplace demands, supervisor support, and co-worker support. In this final model, blue-collar workers and farmers still had more than a two-fold higher rate of AMI compared to white-collar workers.

This is one of few studies (Duijkers et al., 1988; Nordby et al., 1995; Somova et al., 1995; van Loon et al., 2001) to test the John Henryism hypothesis in a non-U.S. population. The first non-U.S. based study, conducted by Duijkers et al. in 1988, used data from a small community sample of 20-59 year old Dutch men and women (Duijkers et al., 1988). Using education to index SEP, they found support for the hypothesis among men, but not women. The remaining two, non-U.S. studies produced either null findings or did not test John Henryism by SEP interactions (Nordby et al., 1995; van Loon et al., 2001). Interestingly, there are strong parallels between John Henry, the legendary and determined 19th century African American unskilled worker and the widely embraced concept, among Finns, of "Sisu," generally defined as a special inner strength and determination to persist and overcome adversity even in the face of considerable odds (Kolehmainen, 1957; Lucas and Buzzanell, 2004). The shared psychological underpinnings of John Henryism and Sisu may have infused the questions used to define the former with special resonance for this sample of Finnish men.

Some may call into question the appropriateness of applying the concept of John Henryism to a non-U.S. and non-African American population. The notion that John Henryism is a construct designed to explain the health consequences of adversity facing African Americans, exclusively, is a misconception. The first bi-racial study of the hypothesized joint influence of John Henryism and SEP on cardiovascular health did not presume that the health effects would be specific to African Americans (James et al., 1987). It just happened that, in this first study that included U.S. Whites, the hypothesized association was found among Blacks, but not Whites. John Henryism is no more race-specific than Type A behavior; and further, none of the items in the John Henryism Scale makes reference to race, ethnicity, gender or SEP. From the outset, the research objective was to develop a valid measure of an individual's predisposition to engage difficult social and economic stressors with persistent, high-effort coping, i.e., John Henryism. However, it was reasonable to expect these stressors to vary in both frequency and intensity by race/ethnicity, and SEP. In addition, it is possible that when social status in a society is defined by both race and class, as is true for the U.S., the "John Henryism effect" should be most evident in the group that is disadvantaged on both dimensions; e.g., African Americans. In contrast, when social status is defined largely by social class (e.g., occupation), as has been the case in Europe, the "John Henryism Effect" should be evident among Whites in lower SEP positions. We acknowledge that this is highly speculative, but it is one way of making sense of the absence of the hypothesized effect, at least so far, in U.S. Whites and its presence among men in Holland (Duijkers et al., 1988) and in Finland. Hence, this longitudinal test of the John Henryism Hypothesis in relation to risk of fatal and non-fatal AMI in a cohort of Finnish men is an important step towards understanding the generality of the hypothesis beyond African Americans in the U.S. South.

Another strength of our study is the use of four measures of socioeconomic position, including childhood socioeconomic position as well as adulthood measures of education, income, and occupational status. Subramanyam et al. employed similar measures of SEP when testing the John Henryism hypothesis in the Jackson Heart Study; but, as noted above, they found only a borderline statistically significant SEP x John Henryism interaction for income, and this only for men (Subramanyam et al., 2013). As is well known, no gold standard exists to measure SEP; hence, the choice of which measure to use depends on the context and the research question. In the current study, we found statistically significant support for the hypothesis only for occupation, though the other SEP measures (childhood SEP, education, and income) produced trends in the expected direction.

Some evidence suggests that for U.S.-based studies, education and income are stronger predictors of cardiovascular health whereas outside the U.S., occupational status seems to be a stronger predictor (Adler et al., 2008; Havranek et al., 2015; van Rossum et al., 2000). For example, the evidence linking social factors to cardiovascular risk among British civil servants in the Whitehall and Whitehall-II studies was most robust for employment grade (a measure of occupational status unique to civil servants) (van Rossum et al., 2000). Additionally, Adler and colleagues (Adler et al., 2008) examined the association between subjective social status (SSS) and objective measures of socioeconomic position, and the associations of these measures with health outcomes among British civil servants within the Whitehall-II Study and among U.S. Black and Whites within CARDIA. They found that occupation was a more important determinant of SSS within the Whitehall Study, but education and income were stronger predictors among U.S. whites. In our study we found clear trends of increasing rates of AMI with increasing education and income, and blue and white-collar workers had higher rates than white-collar workers in bivariate associations. However, there was no association between AMI and childhood socioeconomic position, measured by parents' education and occupation, number of rooms in the home, size of the parents' farm, and perception of family wealth. This measure may be subject to recall bias, and it should be noted that reports from the Kuopio Heart Study found no associations between childhood SEP and total mortality, cardiovascular disease mortality, or acute coronary 
events (Kauhanen et al., 2006; Lynch et al., 1994b).

The limitations of our study also warrant comment. Although this was a longitudinal study, and we controlled for an extensive set of sociodemographic, behavioral, psychosocial, and biological risk factors at baseline, we did not include time-varying covariates. The fact that our findings were robust to these adjustments, while reassuring, does not completely eliminate the potential for residual confounding. Although this large set of adjustment variables may also raise concerns of multi-collinearity among study covariates, our analyses produced little evidence of this potential source of bias. This raises an important question about the potential mechanisms that underlie the reported associations. Future studies should consider the role of two important pathways, including psychosocial stress and inflammation. For example, a number of inflammatory markers such as C-reactive protein and IL-6 have been examined as important determinants of cardiovascular health and central to measures of accelerated aging such as allostatic load (Seeman et al., 2001b). A final limitation of our study is the potential for missingness across study covariates to bias our results. Two variables in particular, John Henryism and Type A Behavior, had some missing scale items, and values were imputed using the median score when fewer than 2 items were missing. For the other variables, incomplete scale scores were considered missing and analyses were restricted to individuals with complete data on all study covariates. Even though there was only a small degree of missingness in our study, (e.g., less than $2 \%$ missingness among individuals who met all eligibility criteria) we acknowledge that there is still potential for some bias. Our study provides strong support for the John Henryism hypothesis vis a vis social determinants of elevated AMI risk in a well-characterized cohort of middle-aged Finnish men. In addition, our findings underscore the potential generality beyond African Americans of an adverse impact on cardiovascular health associated with repetitive high effort coping with social and economic adversity. More studies that investigate the generality of the John Henryism hypothesis to important CVD outcomes in populations that vary by race/ethnicity and geographical setting are necessary. More research is also needed to clarify the biological mechanisms responsible for the observed John Henryism by SEP interaction as well as the roots of the cultural pressures on vulnerable populations to engage, often unwisely, in repetitive high-effort coping with social and economic adversity.

\section{Funding}

This work was supported in part by an internal award from the Kuopio Ischemic Heart Disease Risk Factor Study [5R01HL044199] and the Michigan Interdisciplinary Center for Social Inequality, Mind \& Body [5R24HD047861]. Dr. Mujahid is funded by the National Heart, Lung, and Blood Institute of the National Institutes of Health [5K01HL115494].

\section{Appendix A. Supplementary data}

Supplementary data related to this article can be found at http:// dx.doi.org/10.1016/j.socscimed.2016.11.034.

\section{References}

Adams, J., Aubert, R., Clark, V., 1998. The relationship among John Henryism, hostility, perceived stress, social support, and blood pressure in African-American college students. Ethn. Dis. 9, 359-368.

Adler, N., Singh-Manoux, A., Schwartz, J., Stewart, J., Matthews, K., Marmot, M.G., 2008. Social status and health: a comparison of British civil servants in Whitehall-II with European- and African-Americans in CARDIA. Soc. Sci. Med. 66, 1034-1045.
Barker, D.J., 1995. Fetal origins of coronary heart disease. BMJ 311, 171-174.

Chobanian, A.V., Bakris, G.L., Black, H.R., Cushman, W.C., Green, L.A., Izzo Jr., J.L., et al., 2003. The seventh report of the joint national committee on prevention, detection, evaluation, and treatment of high blood pressure: the JNC 7 report. Jama 289, 2560-2571.

D'Atri, D.A., Ostfeld, A.M., 1975. Crowding: its effects on the elevation of blood pressure in a prison setting. Prev. Med. 4, 550-566.

Dressler, W.W., Bindon, J.R., Neggers, Y.H., 1998. John Henryism, gender, and arterial blood pressure in an African American community. Psychosom. Med. 60, 620-624.

Duijkers, T.J., Drijver, M., Kromhout, D., James, S.A., 1988. “John Henryism” and blood pressure in a Dutch population. Psychosom. Med. 50, 353-359.

Everson-Rose, S.A., Lewis, T.T., 2005. Psychosocial factors and cardiovascular diseases. Annu. Rev. Public Health 26, 469-500.

Everson, S.A., Kaplan, G.A., Goldberg, D.E., Salonen, R., Salonen, J.T., 1997a. Hopelessness and 4-Year progression of carotid atherosclerosis : the Kuopio Ischemic heart disease risk factor study. Arterioscler. Thromb. Vasc. Biol. 17, 1490-1495.

Everson, S.A., Kauhanen, J., Kaplan, G.A., Goldberg, D.E., Julkunen, J., Tuomilehto, J., et al., 1997b. Hostility and increased risk of mortality and acute myocardial infarction: the mediating role of behavioral risk factors. Am. J. Epidemiol. 146, $142-152$.

Harburg, E., Erfurt, J.C., Chape, C., Hauenstein, L.S., Schull, W.J., Schork, M.A., 1973. Socioecological stressor areas and black-white blood pressure: detroit. J. Chronic Dis. 26, 595-611.

Haritatos, J., Mahalingam, R., James, S.A., 2007. John Henryism, self-reported physical health indicators, and the mediating role of perceived stress among high socio-economic status Asian immigrants. Soc. Sci. Med. 64, 1192-1203.

Havranek, E.P., Mujahid, M.S., Barr, D.A., Blair, I.V., Cohen, M.S., Cruz-Flores, S., et al., 2015. Social determinants of risk and outcomes for cardiovascular disease: a scientific statement from the American heart association. Circulation. 134, $873-898$.

Ihanainen, M., Salonen, R., SeppÃ̈anen, R., Salonen, J.T., 1989. Nutrition data collection in the Kuopio Ischaemic heart disease risk factor study: Nutrient intake of middle-aged eastern finnish men. Nutr. Res. 9, 597-604.

James, S.A., Hartnett, S.A., Kalsbeek, W.D., 1983. John Henryism and blood pressure differences among black men. J. Behav. Med. 6, 259-278.

James, S.A., Keenan, N.L., Strogatz, D.S., Browning, S.R., Garrett, J.M., 1992. Socioeconomic status, John Henryism, and blood pressure in black adults. The pitt county study. Am. J. Epidemiol. 135, 59-67.

James, S.A., Strogatz, D.S., Wing, S.B., Ramsey, D.L., 1987. Socioeconomic status, John Henryism, and hypertension in blacks and whites. Am. J. Epidemiol. 126, 664-673.

Johnson, G.B., 1929. John Henry; Tracking Down a Negro Legend. The University of North Carolina press, Chapel Hill,.

Kaplan, G.A., Keil, J.E., 1993. Socioeconomic factors and cardiovascular disease: a review of the literature. Circulation 88, 1973-1998.

Kaplan, G.A., Salonen, J.T., 1990. Socioeconomic conditions in childhood and Ischemic-heart-disease during middle-age. Br. Med. J. 301, 1121-1123.

Kaplan, G.A., Turrell, G., Lynch, J.W., Everson, S.A., Helkala, E.L., Salonen, J.T., 2001. Childhood socioeconomic position and cognitive function in adulthood. Int. J. Epidemiol. 30, 256-263.

Kasl, S.V., Cobb, S., 1970. Blood pressure changes in men undergoing job loss - a preliminary report. Psychosom. Med. 32, 19.

Kauhanen, L., Lakka, H.-M., Lynch, J.W., Kauhanen, J., 2006. Social disadvantages in childhood and risk of all-cause death and cardiovascular disease in later life: a comparison of historical and retrospective childhood information. Int. J. Epidemiol. 35, 962-968.

Kolehmainen, J., 1957. Introduction. In: Tokoi, O. (Ed.), Sisu: Even through a Stone Wall: the Autobiography of Oskari Tokoi. Robert Speller and Sons, New York, pp. ix-xiii.

Lakka, H.M., Lakka, T.A., Tuomilehto, J., Salonen, J.T., 2002. Abdominal obesity is associated with increased risk of acute coronary events in men. Eur. Heart J. 23, $706-713$.

Lakka, T.A., Nyyssonen, K., Salonen, J.T., 1994. Higher levels of conditioning leisure time physical activity are associated with reduced levels of stored iron in Finnish men. Am. J. Epidemiol. 140, 148-160.

Lim, S.S., Vos, T., Flaxman, A.D., Danaei, G., Shibuya, K., Adair-Rohani, H., et al., 2012. A comparative risk assessment of burden of disease and injury attributable to 67 risk factors and risk factor clusters in 21 regions, 1990-2010: a systematic analysis for the Global Burden of Disease Study 2010. Lancet 380, 2224-2260.

Logan, J.G., Barksdale, D.J., James, S.A., Chien, L.C., 2015. John Henryism active coping, acculturation, and psychological health in Korean immigrants. J. Transcult. Nurs. http://dx.doi.org/10.1177/1043659615615402.

Lozano, R., Naghavi, M., Foreman, K., Lim, S., Shibuya, K., Aboyans, V., et al., 2012. Global and regional mortality from 235 causes of death for 20 age groups in 1990 and 2010: a systematic analysis for the Global Burden of Disease Study 2010. Lancet 380, 2095-2128.

Lucas, K., Buzzanell, P.M., 2004. Blue-collar work, career, and success: occupational narratives of Sisu. J. Appl. Commun. Res. 32, 273-292.

Lynch, J., Krause, N., Kaplan, G.A., Tuomilehto, J., Salonen, J.T., 1997. Workplace conditions, socioeconomic status, and the risk of mortality and acute myocardial infarction: the Kuopio Ischemic heart disease risk factor study. Am. J. Public Health 87, 617-622.

Lynch, J.W., Kaplan, G.A., Cohen, R.D., Kauhanen, J., Wilson, T.W., Smith, N.L., et al., 1994a. Childhood and adult socioeconomic status as predictors of mortality in 
Finland. Lancet 343, 524-527.

Lynch, J.W. Kaplan, G.A., Cohen, R.D., Tuomilehto, J., Salonen, J.T., 1996. Do cardiovascular risk factors explain the relation between socioeconomic status, risk of all-cause mortality, cardiovascular mortality, and acute myocardial infarction? Am. J. Epidemiol. 144, 934-942.

Lynch, J.W., Kaplan, G.A., Cohen, R.D., Wilson, T.W., Smith, N.L., Kauhanen, J., et al., 1994b. Childhood and adult socioeconomic status as predictors of mortality in Finland. Lancet 343, 524-527.

McEwen, B.S., Gianaros, P.J., 2010. Central role of the brain in stress and adaptation: links to socioeconomic status, health, and disease. Ann. N. Y. Acad. Sci. 1186, 190-222.

McKetney, E.C., Ragland, D.R., 1996. John Henryism, education, and blood pressure in young adults. The CARDIA study. Coronary artery risk development in young adults study. Am. J. Epidemiol. 143, 787-791.

Merritt, M.M., Bennett, G.G., Williams, R.B., Sollers 3rd, J.J., Thayer, J.F., 2004. Low educational attainment, John Henryism, and cardiovascular reactivity to and recovery from personally relevant stress. Psychosom. Med. 66, 49-55.

Nordby, G., Ekeberg, O., Knardahl, S., Os, I., 1995. A double-blind study of psychosocial factors in 40-year-old women with essential hypertension. Psychother Psychosom. 63, 142-150.

Obrist, P.A., Gaebelein, C.J., Teller, E.S., Langer, A.W., Grignolo, A., Light, K.C., et al., 1978. The relationship among heart rate, caratid $\mathrm{dP} / \mathrm{dt}$, and blood pressure in humans as a function of the type of stress. Psychophysiology 15, 102-115.

Ostfeld, A.M., Shekelle, R.B., 1967. Psychological variables and blood pressure. In: Stamler, J., Stamler, R., Pullman, T.N. (Eds.), The Epidemiology of Hypertension. Grune and Stratton, New York.

Power, C., Matthews, S., 1997. Origins of health inequalities in a national population sample. Lancet 350, 1584-1589.

Rose, G.A., Blackburn, H., Gillum, R.F., Prineas, R.J., 1982. Cardiovascular Survey Methods. World Health Organization, Geneva, Switzerland.

Salonen, J.T., 1988. Is there a continuing need for longitudinal epidemiologic research? The Kuopio Ischaemic heart disease risk factor study. Ann. Clin. Res. 20, 46-50.

Salonen, J.T., Nyyssönen, K., Korpela, H., Tuomilehto, J., Seppänen, R., Salonen, R., 1992. High stored iron levels are associated with excess risk of myocardial infarction in eastern Finnish men. Circulation 86, 803-811.

Salonen, J.T., Salonen, R., Seppänen, K., Rauramaa, R., Tuomilehto, J., 1991. HDL,
HDL2, and HDL3 subfractions, and the risk of acute myocardial infarction. A prospective population study in eastern Finnish men. Circulation 84, 129-139.

Seeman, T.E., McEwen, B.S., Rowe, J.W., Singer, B.H., 2001a. Allostatic load as a marker of cumulative biological risk: MacArthur studies of successful aging. Proc. Natl. Acad. Sci. 98, 4770-4775.

Seeman, T.E., McEwen, B.S., Rowe, J.W., Singer, B.H., 2001b. Allostatic load as a marker of cumulative biological risk: MacArthur studies of successful aging. Proc. Natl. Acad. Sci. U. S. A. 98, 4770-4775.

Somova, L.I., Diarra, K. Jacobs, T.Q., 1995. Psychophysiological study of hypertension in black, indian and white African students. Stress Med. 11, 105-111.

Stanton, M.V., Jonassaint, C.R., Williams, R.B., James, S.A., 2010. Socioeconomic status moderates the association between John Henryism and NEO PI-R personality domains. Psychosom. Med. 72, 141-147.

Subramanyam, M.A., James, S.A., Diez-Roux, A.V., Hickson, D.A., Sarpong, D., Sims, M., et al., 2013. Socioeconomic status, John Henryism and blood pressure among African-Americans in the Jackson heart study. Soc. Sci. Med. 93, 139-146.

Tuomilehto, J., Arstila, M., Kaarsalo, E., Kankaanpaa, J., Ketonen, M., Kuulasmaa, K., et al., 1992. Acute myocardial infarction (AMI) in Finland-baseline data from the FINMONICA AMI register in 1983-1985. Eur. Heart J. 13, 577-587.

van Loon, A.J.M., Tijhuis, M., Surtees, P.G., Ormel, J., 2001. Personality and coping: their relationship with lifestyle risk factors for cancer. Personal. Individ. Differ 31, 541-553.

van Rossum, C.T., Shipley, M.J., van de Mheen, H., Grobbee, D.E., Marmot, M.G., 2000 Employment grade differences in cause specific mortality. A 25 year follow up of civil servants from the first Whitehall study. J. Epidemiol. Community Health 54, 178-184.

Weinrich, S.P., Weinrich, M.C., Keil, J.E., Gazes, P.C., Potter, E., 1988. The John Henryism and Framingham type A scales. Measurement properties in elderly blacks and whites. Am. J. Epidemiol. 128, 165-178.

Wilson, T.W., Kaplan, G.A., Kauhanen, J., Cohen, R.D., Wu, M., Salonen, R., et al., 1993. Association between plasma fibrinogen concentration and five socioeconomic indices in the Kuopio Ischemic heart disease risk factor study. Am. J. Epidemiol. 137, 292-300.

Wright, L.B., Treiber, F.A., Davis, H., Strong, W.B., 1996. Relationship of John Henryism to cardiovascular functioning at rest and during stress in youth. Ann. Behav. Med. 18, 146-150. 